\title{
Persistence of T. pallidum and its significance in penicillin-treated seropositive late syphilis
}

\author{
L. YOGESWARI AND C. W. CHACKO \\ From the Central V.D. Reference Laboratory, Institute of Venereology, Madras Medical College, Madras-3, India
}

The observation of $T$. pallidum-like organisms reported by Collart, Borel, and Durel (1962, a, b, c, 1964) in the lymph nodes of both men and rabbits in seroreactive treated syphilis and the stimulating work of Smith and Israel (1967 a, b, 1968) on intraocular treponemes in late syphilis have created much interest in the survival and virulence of $T$. pallidum in tissues and body fluids in cases of untreated and treated, latent and late stages of seropositive syphilis in man.

Research was undertaken with the aim of searching for and demonstrating virulent $T$. pallidum in the tissues and fluids of humans naturally infected with syphilis and of rabbits artificially infected with $T$. pallidum before and after adequate treatment with standard doses of penicillin. Attempts were then made to correlate the presence of $T$. pallidum with the persistent reactivity of the standard and specific serological tests for syphilis in such subjects. If the findings of earlier workers could be reproduced and confirmed the results obtained would be expected to contribute much to our fundamental knowledge of syphilis and to the practical control of treponemal infections.

\section{Material and methods}

\section{EXPERIMENTAL SYPHILIS IN RABBITS}

A total of 37 young adult male rabbits had been inoculated intratesticularly with Nichols virulent strain of $T$. pallidum 2 weeks to 52 months previously.

In 36 rabbits bilateral orchitis developed in an average incubation period of 10 days and their sera became reactive to both the VDRL and TPI tests. Results of serial testing with the quantitative VDRL slide test varied from nonreactive to a maximum titre of $1: 128$, while the TPI tests were reactive except when cases were tested in the earliest stages of infection. The TPI tests were performed by the technique as modified by Metzger and Ruczkowska (1962) and the VDRL tests according to the procedure in the Manual of Serologic Tests for Syphilis (1964).

All 36 successfully infected rabbits were seroreactive to the VDRL and TPI tests when the experiments were

Received for publication April 22, 1971

Paper presented at the International Colloquium on Late Treponematoses, Miami, Florida, U.S.A., on January 4 to 8, 1971 begun. Lymph node material from 26 untreated rabbits was tested for the presence of $T$. pallidum by transfer to normal rabbits and by examination of the smears.

To alter the immune response so that latent disease might become manifest, nine rabbits out of the group of 26 with untreated latent syphilitic infection, were given cortisone. Each rabbit received $200 \mathrm{mg}$. cortisone acetate (Merck Sharp and Dohme) given in 10 days. The rabbits were followed clinically for 6 to 12 months and VDRL and TPI tests were performed on their sera at periodic intervals: 6 to 12 months later inguinal and popliteal lymph node material was transferred to normal rabbits intratesticularly and lymph node smears were examinedo for T.pallidum.

Each of the ten remaining rabbits out of the 36 with latent infection received benzathine penicillin $G$ in divided doses of 50,000 Oxford units $/ \mathrm{kg}$. body weight to a total of 200,000 units of the antibiotic. This group was also followed clinically for 6 to 12 months; VDRL and TPI tests were performed periodically. Their inguinal and popliteal lymph node material was transferred to normal rabbits intratesticularly 6 to 12 months after completion of specific penicillin treatment and lymph node smears were examined for $T$. pallidum.

\section{HUMAN SYPHILIS}

43 cases of syphilis were studied; two of early syphilis, one untreated and one inadequately treated, one of untreated ocular syphilis, and the rest adequately treated early and late latent, congenital, and late symptomatic cases. Inguinal lymph node tissue, aortic tissue, brain tissue, bone marrow, and aqueous humour from the human cases were examined for treponemes.

\section{DEMONSTRATION OF TREPONEMES}

The following methods were used:

(1) Examination by darkfield microscopy.

(2) Microscopic examination of tissue-impression smears of incised lymph nodes stained by Dunoyer's modification of Dieterle's silver impregnation technique (Collart and others, 1962a).

(3) Darkfield microscopic examination of tissue impression smears of incised lymph nodes, other tissues, and smears of aqueous humour stained by the fluorescent antibody method.

Both 'indirect' and 'direct' methods for fluorescent antibody tissue staining were used. 
The indirect method was that described in the 'Revised Technique for the Fluorescent Treponemal Antibody Absorption (FTA-ABS) Test dated July 19, 1967' issued by the VDRL, Atlanta, Georgie, U.S.A.

The direct method was the 'Provisional Technique of June 15, 1967, for the Direct Immunofluorescent Indentification of Treponema pallidum in Body Fluids and Tissue Sections' issued by the VDRL, Atlanta, Georgia, U.S.A. The stained smears were examined on a Reichert monocular darkfield research microscope, using an ultra violet light source and a high power dry objective. A combination of BG 12 exciting filter and 1.5/OG 1 barrier filter was used with an HBO 200 mercury vapour lamp as the light source. Tissue smears of testes from rabbits with acute orchitis were stained as controls. Prolonged and painstaking search of slides was involved before $T$. pallidum-like organisms could be spotted. As soon as the organisms were visualized photomicrographs were taken using the Reichert camera and the only available $35 \mathrm{~mm}$. photographic film, ASA 100.

(4) Staining of histological sections of lymph node with Levaditi's silver-staining method (Biological Stain Commission, 1960).

(5) Staining of histological sections of lymph nodes with the silver impregnation method of Jayaraj (1964).

(6) To demonstrate the presence of viable $T$. pallida and their infectiousness, inguinal and popliteal lymph nodes from each animal were dissected out and material was transferred in suspension to normal rabbits by intratesticular inoculation. Suspensions were prepared by macerating lymph nodes, grinding them thoroughly in a sterile mortar with 50 per cent. normal rabbit-serum saline and centrifuging the suspension at 2,500 r.p.m. for $5 \mathrm{~min}$. in an angle centrifuge. The development of darkfield positive lesions and a specific serological response in the recipient rabbits was taken as proof of the presence of live and virulent $T$. pallida.

\section{Results}

These are analysed in Tables I and II.

\section{Rabbits}

Table I shows that $T$. pallidum could be demonstrated in the lymph nodes of seventeen seroreactive rabbits by the animal infectivity test and in the lymph node tissue of four rabbits out of seventeen by the FA staining technique. None of these seventeen infected rabbits had been treated with penicillin.

In nine rabbits with untreated latent infection which gave negative results to animal infectivity tests and which were given cortisone to reactivate their infection and also in ten infected rabbits which were treated with penicillin, $T$. pallidum was not demonstrated in the lymph node tissues by any of the various staining procedures or by infectivity tests.

\section{Human cases}

Table II shows that it was possible to demonstrate $T$. pallidum by the rabbit infectivity test by injecting blood and lymph node tissue from a patient with early latent syphilis, inadequately treated with penicillin and seropositive.

\section{TABLE 1 Results of experimental syphilis in rabbits}

No. of rabbits inoculated with Nichols strain of $T$. pallidum

No. successfully infected

No. not infected

Duration of infection

Serological status of untreated rabbits at the time of animal infectivity test and tissues smear studies :

No. of untreated rabbits proved to be actively infected on lymph node transfer to normal rabbits

Demonstration of $T$. pallidum in lymph node tissue of untreated syphilitic rabbits by:

(1) Darkfield microscopy

(2) Silver staining

(3) FA staining

No. of rabbits given cortisone to reactivate untreated latent infection

Serological status at the time of animal infectivity test and tissue smear studies

No. of cortisone-treated rabbtis that proved infective by lymph node transfer to normal rabbits

Demonstration of $T$. pallidum in lymph node tissue of cortisone-treated rabbits by:

(1) Darkfield microscopy

(2) Silver staining

(3) FA staining

No. of rabbits treated with penicillin

Serological status at the time of animal infectivity test and tissue smear studies

No. of penicillin-treated rabbits proved infective by lymph node transfer to normal rabbits Demonstration of $T$. pallidum in lymph node tissue of penicillin-treated rabbits by:
(1) Darkfield microscopy
(2) Silver staining
(3) FA staining

37

36

2 weeks to 52 months

All reactive to VDRL and TPI tests

17 out of 26

Not successful

Not successful

Successful in 4

9

6 had persistent reactive serology

3 that were seroreactive reverted to nonreactivity

None

Not successful

Not successful

Not successful

10

7 had persitent reactive serology

3 became nonreactive

None

Not successful

Not successful

Not successful 
TABLE II Results of the study of syphilis for the demonstration of T. pallidum in human tissues and aqueous humour

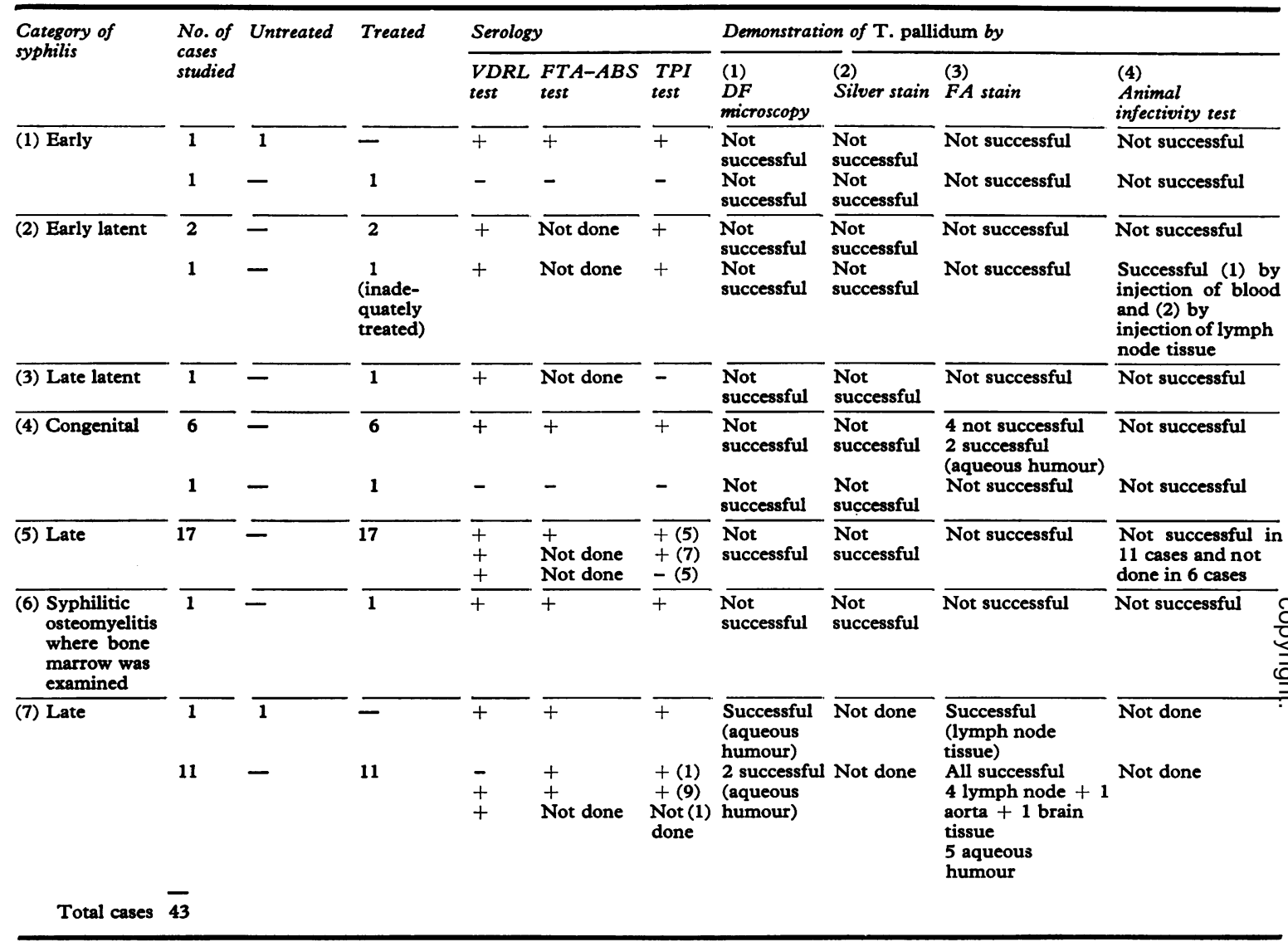

It will also be seen that $T$. pallidum-like organisms were successfully demonstrated in the aqueous humour and lymph node tissue from one case of untreated late ocular syphilis.

T. pallidum-like organisms were also demonstrated in the aqueous humour of seven cases and in the lymph node tissue smears of four cases (in one of which the organisms could be demonstrated both in the aqueous humour and the lymph node tissue). Finally, the organisms were found in the aortic tissue of one and in the brain tissue of another case.

All these thirteen cases were ones of adequately treated late syphilis and all had shown persistent seroreactivity when treponemes were sought in tissues or fluids.

REPORTS OF TREATED CASES IN WHICH $T$. pallidum-LIKE ORGANISMS WERE SUCCESSFULLY DEMONSTRATED

Case 1, a 29-year-old male, was first seen at the Insti- tute of Venereology in November, 1966, with progressive loss of vision of 2 months' duration. He was referred from the Ophthalmic Clinic as a case of bilateral optic atrophy with a visual acuity of $1 / 60$ in the right eye and 3/60 in the left.

\section{Examination}

The perimetry chart showed concentric contraction of the visual field on the left side. Serum VDRL, TPI and FTA-ABS tests were strongly reactive. The CSF showed 10 cells per cu. mm., $68 \mathrm{mg}$. per cent. protein and a reactive VDRL test.

\section{Treatment}

From 1966 to 1968 he was given six courses of antisyphilitic treatment, each course consisting of 12 million units of PAM, $60 \mathrm{mg}$. cortisone in divided doses, and fever therapy with TAB vaccine in graded doses. Despite intensive treatment the vision deteriorated and in 1968 the right eye was blind and visual acuity in the left eye was reduced to $1 / 60$. 


\section{Result}

Paracentesis of the anterior chamber was performed on the right eye 12 days after the last treatment; the aqueous humour was examined by darkfield microscopy and FA staining and $T$. pallidum-like organisms were seen (Fig. 1).

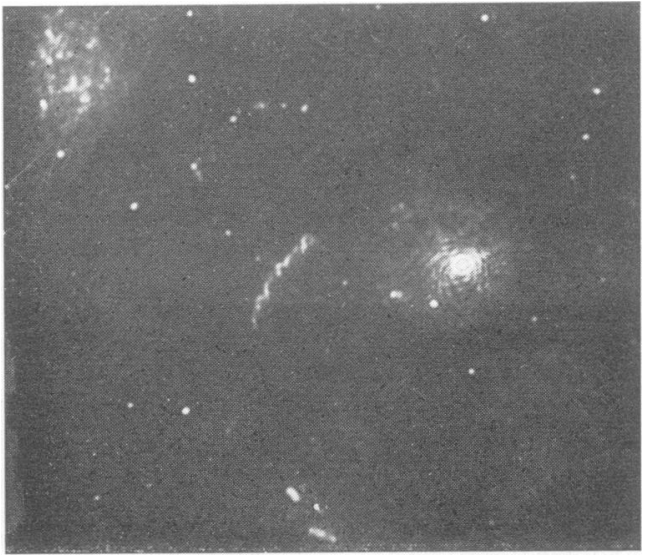

FIG. 1 Fixed smear of aqueous humour from Case 1, stained by direct fluorescent antibody technique, showing one T. pallidum-like organism. $\times 625$

Case 2, a 26-year-old male, was seen at the Institute of Venereology in April, 1969, when he was referred by the Ophthalmic clinic with chronic iritis of both eyes and VI nerve paralysis on the right side. His previous history revealed that he had had a genital sore 18 months before the onset of the eye lesions for which he was given one injection of penicillin.

\section{Examination}

The visual acuity was $2 / 60$ in the right eye and $3 / 60$ in the left. The fundi appeared to be normal. VDRL, FTA-ABS, and TPI tests on the serum were positive, but the CSF was inactive and the VDRL test negative.

\section{Treatment}

He was given 12 million units PAM and fever therapy with graded doses of $T A B$ vaccine, and the eyes were treated with atropine and cortisone eye ointments.

\section{Result}

50 days later paracentesis of the anterior chamber of the right eye was performed and darkfield microscopy of the aqueous humour revealed motile and non-motile spirochaetes resembling $T$. pallidum; these organisms were also detected by fluorescent antibody staining.

Case 3, a 50-year-old male, was first seen in April, 1966 , with defective vision in both eyes of 2 years' duration. He was referred by the Ophthalmic clinic as a case of syphilitic optic atrophy with tabes dorsalis; aortic regurgitation was also present. He had had a genital sore in 1932 for which he had received only indigenous therapy.

\section{Examination}

Serological tests for syphilis were positive and the CSF was also active.

\section{Treatment}

He was treated with a total of 55.2 m.u. PAM over a period of 3 years by which time the cerebrospinal fluid had reverted to normal.

Result

Both the aqueous humour and the inguinal lymph node tissue were examined 15 days after the last treatment and showed fluorescent treponemes that looked like $T$. pallidum (Fig. 2).

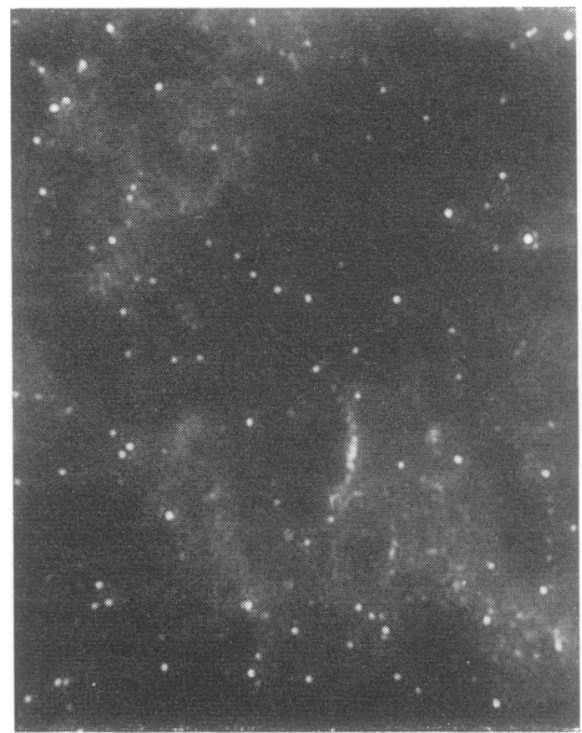

FIG. 2 Tissue impression smear of lymph node from Case 3, stained by direct fluorescent antibody technique, showing $\mathrm{T}$. pallidum-like organisms in central area. $\times 625$

Case 4, a 50-year-old male, first seen at the Institute of Venereology in November, 1969, was referred by the Ophthalmic Clinic with defective vision in the right eye of 2 years' duration. For this complaint he had received thirty streptomycin injections in another hospital. He stated that he had had syphilis when he served in the army in 1946 and was then treated with penicillin. There was evidence of a previous genital sore.

\section{Examination}

The left eye was normal, but the right pupil was irregular and the vision was reduced to perception of light. There was a lenticular haze and there were patches of vitreous haemorrhage. The serum VDRL test was negative while the TPI and FTA-ABS tests were positive. The CSF was normal. 
Result

Paracentesis of the anterior chamber of his right eye was performed and the aqueous humour showed non-motile $T$. pallidum-like organisms by darkfield microscopy; these organisms showed fluorescence after FA staining.

Case 5, a 39-year-old male, first seen in January, 1970, with double vision of 4 months' duration, was referred by the Ophthalmic Clinic as a case of bilateral sixth nerve palsy.

\section{Examination}

The visual acuity was $3 / 60$ in the right eye and $\frac{1}{2} / 60$ in the left. Ophthalmoscopy revealed primary optic atrophy. The serum was reactive to the VDRL, FTA-ABS, and TPI tests. The CSF contained 4 cells $/ \mathrm{cu}$. $\mathrm{mm}$. and 48 mg. per cent. protein and was nonreactive to the VDRL test. The colloidal gold test gave a first zone curve.

\section{Treatment}

He was given $21 \mathrm{~m} . u$. penicillin and fever therapy with TAB vaccine.

\section{Result}

Paracentesis of the left anterior chamber was performed 10 days after the last treatment and $T$. pallidum-like organisms were seen in the aqueous humour not by darkfield microscopy but by immunofluorescent staining.

Case 6, an 11-year-old girl, was referred to the Institute of Venereology from the Government Ophthalmic Hospital in October, 1969, as a case of late congenital syphilis with active interstitial keratitis of the right eye.

\section{Examination}

The left eye was normal. The serum was reactive to the VDRL, FTA-ABS, and TPI tests, but the CSF was normal.

\section{Treatment}

She was given 24 m.u. PAM and fever therapy with TAB vaccine and topical treatment with 1 per cent. atropine and hydrocortisone eye drops.

\section{Result}

Paracentesis of the right anterior chamber was performed 5 months after the last treatment, and the aqueous humour showed $T$. pallidum-like organisms on FA staining.

The patient is still under observation; the right cornea is still hazy and she has intermittent photophobia and lacrimation.

Case 7, a 10-year-old girl, was referred to the Institute of Venereology from the Government Ophthalmic Hospital in March, 1970, as a case of late congenital syphilis with Clutton's joints of the ankles and knees and acute bilateral interstitial keratitis.

\section{Examination}

She had marked photophobia and lacrimation and the visual acuity was reduced to counting fingers close to the face. The serum was reactive to the VDRL, FTA-ABS, and TPI tests, but the CSF was normal.

\section{Treatment}

She was given 24 m.u. PAM and fever therapy with TAB vaccine.

\section{Result}

Paracentesis of the right anterior chamber was performed 3 months after the last treatment and the aqueous humour showed $T$. pallidum-like organisms by FA staining.

Case 8, a 35-year-old male, was first seen in June, 1961, with muscular weakness on the right half of the body. He had had a genital sore in 1951 and had received an unknown amount of penicillin.

\section{Examination}

There was evidence of previous genital infection and inguinal lymphadenopathy, and residual signs of rightsided hemiplegia. Serum tests for syphilis were positive, but the CSF was normal.

\section{Treatment}

He was given 6 m.u. PAM.

In 1969 the right-sided hemiparesis was still present the serum reacted to the VDRL, FTA-ABS, and TPK tests and the CSF remained normal. He was again given 6 m.u. PAM.

\section{Result}

A week after the last treatment the inguinal lymph node tissue showed fluorescing $T$. pallidum-like organisms on FA staining.

Case 9, a 40-year-old male, was brought to the hospital by his relations in April, 1956, with symptoms of insanity. He had had a genital sore in 1942 and had been treated with fifteen injections of arsenic.

\section{Examination}

There were multiple depigmented scars all over the body, slurred speech, tremors of the tongue and fingers, hyperreflexia, and extensor plantar responses. The serum tests for syphilis were positive and the CSF showed 12 cells/ cu. $\mathrm{mm}$. and $80 \mathrm{mg}$. per cent. protein, and was reactive to VDRL test. The colloidal gold test gave a first zone curve. The case was diagnosed as one of general paralysis of the insane.

\section{Treatment}

He received 35.4 m.u. penicillin (in 1956, 1967, 1969), and fever therapy induced with B.T. malarial blood giving a total of $54 \mathrm{hrs}$ above $103^{\circ} \mathrm{F}$.

\section{Result}

The lymph node tissue revealed $T$. pallidum-like organisms on FA staining.

This case is noteworthy, in that despite arsenical treatment of a genital sore and the successful induction of 
malarial fever therapy and three 'adequate' courses of penicillin, $T$. pallidum-like organisms were still identifiable by FA staining 27 years after the appearance of the genital sore and 13 years after the initial treatment for GPI.

Case 10, a 45-year-old male, was admitted to hospital in August, 1956, with a history of convulsions resulting in unconsciousness. He had had a genital sore in 1936 followed by rash for which he had received only indigenous treatment.

\section{Examination}

He talked continuously and irrelevantly. There were tremors of the tongue and fingers and the knee and ankle jerks were absent. Serum tests for syphilis were positive. The CSF showed 12 cells/cu. mm.; $72 \mathrm{mg}$. per cent. protein, and was reactive to the VDRL test. The colloidal gold test gave a first zone curve.

\section{Treatment}

He was given a course of 20 g. achromycin, and 24 m.u. PAM in 1956, 1957, and 1958.

\section{Result}

In 1969 the serum was reactive but the CSF was normal, and 11 years after treatment the lymph node tissue showed $T$. pallidum-like organisms by FA staining.

Case 11, a 15-year-old-boy, a member of a tribe from an area where yaws is endemic, came to Madras City for treatment in March, 1969. He had discoloration of the palms and had previously received only indigenous treatment.

\section{Examination}

There was leucomelanoderma of both palms and soles with hyperkeratosis. The serum was reactive to VDRL, FTAABS, and TPI tests, but the CSF was normal.

\section{Treatment}

He was given 12 m.u. PAM.

\section{Result}

A month after the last treatment lymph node tissue was examined and treponemes were found by specific immunofluorescent staining.

Case 12, a 42-year-old male, was admitted to hospital in July, 1969, with a painful swelling of the right side of the chest. He gave a history of having had a genital discharge in $\mathbf{1 9 5 4}$ for which he had received 'injections' (probably penicillin).

\section{Examination}

There were clinical and radiological signs of an aneurysm of the ascending thoracic aorta. The serum was reactive to VDRL, FTA-ABS, and TPI tests.

\section{Treatment}

He was given 12 m.u. PAM and 2 months later the aneurysmal sac was excised by a surgeon.
Result

Tissue smears taken from the neck of the aneurysmal sac revealed $T$. pallidum-like organisms on FA staining.

Case 13, a 35-year-old male, was admitted in March, 1969, to the Government Mental Hospital, where it was reported that the serum and CSF were reactive to the VDRL test for syphilis, and GPI was diagnosed.

\section{Treatment}

He was given 12 m.u. PAM.

\section{Result}

He died in the hospital 4 months after the last treatment and his brain specimen was sent to us for study. Tissue impression smears revealed $T$. pallidum-like organisms on FA staining.

\section{Discussion}

In this study, attempts to demonstrate $T$. pallidum in the inguinal and popliteal lymph nodes of penicillin-treated rabbits with latent syphilis failed in rabbit-infectivity tests and by the silver impregnation and FA staining methods. This was so in ten such rabbits (Table I), seven of which had persistent reactivity and three of which showed no reactivity to the TPI and VDRL tests at the time of transfer. This is in striking contrast to the successful demonstration of viable and virulent $T$. pallidum by rabbit infectivity tests after lymph node transfer in seventeen of 26 rabbits with latent syphilis left untreated for about the same period, all of which showed persistent seroreactivity. In four of these seventeen rabbits it was possible to demonstrate $T$. pallidum by the FA staining method. In the lymph nodes of nine syphilitic rabbits left untreated and later given cortisone in an attempt to reactivate latent infection, $T$. pallidum could not be demonstrated either by the rabbit-infectivity test or by any of the staining methods tried. Of these nine rabbits, six had persistent seroreactivity.

In a series of 43 human cases (42 of syphilis and 1 of yaws), of forty adequately treated with penicillin, 38 showed persistent seroreactivity, and it was possible to demonstrate $T$. pallidum-like organisms by FA staining in thirteen of them. In four of these (Cases 8 to 11) organisms were found in lymph node tissue smears, in seven (Cases 1 to 7 ) in the aqueous humour (of which two (Cases 2 and 4 ) were darkfield positive). Organisms were seen in Case 3 in both aqueous humour and lymph node tissue. Organisms were also found in the aortic tissue smears of Case 12 and in brain tissue smears of Case 13, both by the FA staining technique. However, viability or virulence of the $T$. pallidum-like organisms demonstrated by staining could not be proved by rabbit-infectivity tests. 
There were three cases of untreated or inadequately treated syphilis with persistent seroreactivity. From one case of inadequately treated early latent syphilis, a local strain of $T$. pallidum was isolated both from the lymph node and from blood and was maintained in rabbits in the laboratory. In another case (one of ocular syphilis) $T$. pallidum-like organisms were demonstrated by FA staining of aqueous humour and lymph node tissue but the rabbit-infectivity test could not be done. In the third case all methods of search were unsuccessful.

The demonstration in Cases 1 to 7 of $T$. pallidumlike organisms in the aqueous humour of patients treated for syphilitic involvement of the eye confirmed the earlier findings of Smith and Israel (1967a, b, 1968), Goldman and Girard (1967), Christman, Hamilton, Heaton, and Hoffmeyer (1968), and Rice, Dunlop, Jones, Hare, King, Rodin, Mushin, and Wilkinson (1970). The question again arises of their viability and virulence, and of their actual role in the causation of interstitial keratitis and other ocular lesions. The accessibility of penicillin to the aqueous humour, the future effect of persisting intraocular treponemes, and the use of paracentesis of the anterior chamber for the diagnostic demonstration of $T$. pallidum all have to be considered.

The rare demonstration in our study of $T$. pallidumlike organisms in tissue smears from a syphilitic aortic aneurysm (Case 12) and in brain tissue smears from a patient with GPI (Case 13) is a matter of significance and concern.

The persistence of spiral organisms morphologically resembling $T$. pallidum, in the tissues and body fluids of seropositive syphilitic patients, most of whom have received amounts of penicillin treatment in excess of 'standard' requirements, may cause anxiety to both venereologists and ophthalmologists.

It has not been proved, however, that the organisms seen are definitely $T$. pallidum. Successful inoculation of the rabbit producing darkfield positive lesions is necessary to demonstrate the presence of virulent organisms. Treponemes seem to require acclimatization and a comparatively long incubation period after the initial transfer from man to rabbit, and not every darkfield positive specimen, teeming with treponemes, will infect a rabbit. The test may be difficult, time-consuming, and unpredictable, particularly when the organisms are few and far between, as in late human syphilitic tissues and aqueous humour. Nevertheless, in untreated rabbit syphilis, the infectivity test has been shown to be positive in a high proportion of cases by many workers in this field and has been more or less confirmed in this study; in the adequately treated cases of rabbit syphilis, infectivity tests in recipient rabbits have proved to be negative.

It may be noted in this connection that, in the reports by Collart and others (1962a, b, c, 1964) and Yobs, Clark, Mothershed, Bullard, and Artley (1968), the positive results in rabbit syphilis have not been completely convincing.

In this study and those of Yobs and others (1968), experiments with cortisone have not given satisfactory evidence that cortisone either influences the course of latent syphilis in the rabbit or alters the receptivity of rabbits to infection. In our study syphilitic infection in the rabbit appeared to be cured by standard penicillin therapy as indicated by the negative results of rabbit infectivity tests.

In our cases of untreated rabbit syphilis, wherever $T$. pallidum was shown to persist in tissues and to remain viable and transmissible, there was persistent seroreactivity, as has been reported in other studies. But in treated cases of rabbit syphilis, the persistence of $T$. pallidum and seroreactivity were not always positively correlated; $T$. pallidum could not be demonstrated in all the cases which were reactive in the TPI test.

A significant number of instances of persistente $T$. pallidum in the tissues and body fluids of cases of? treated syphilis in man, in this study and in the series of Collart and others (1962, a, b, c, 1964) and of Yobs, Olansky, Rockwell, and Clark (1965) and Yobs and others (1968), has been based on the demonstration of treponemes in tissues by staining methods, but these organisms did not produce disease on inoculation into normal rabbits. Yet the organisms concerned appeared to be morphologically identical to $T$. pallidum, and stained specifically with fluorescein-labelled anti- $T$. pallidum rabbit globulin and emitted fluorescence under ultra violet light on darkfield microscopy.

If the treponemal forms seen in cases of treated syphilis are considered to be saprophytic, attempts should be made to isolate and grow them in artificial culture media as is possible with Reiter treponemes. This procedure was not carried out in our study or by Collart and Yobs. Successful culture may not only indicate that loss of virulence may have taken place but may also permit further study of morphology and antigenicity.

Our results in human syphilis have largely confirmed those reported by Collart and others (1962 a, b, c, 1964), Yobs and others $(1965,68)$, and Smith and Israel (1967 a, b, 1968) that in a certain significant proportion of cases of adequately treated late human syphilis, organisms indistinguishable from $T$. pallidum could be demonstrated to persist 
in tissues and body fluids. The presence of such treponemes in 'adequately' treated cases raises the question of the efficacy of penicillin therapy in late syphilis. The early studies on the response of syphilis to penicillin were focused on the clinical signs of the disease and subsequent serological changes.

Penicillin therapy, especially when given a long time after the onset of the disease, may not destroy all the treponemes that have remained in the host for several years, and such organisms, although still viable, may have lost their virulence and continue to live within the host as commensals.

If such treponemes persist in the host after treatment they may still be involved in the continued pathogenesis of the disease, by leading to the development of a state of allergy or hypersensitivity which, on exposure to fresh treponemes, renews clinical activity such as is seen in interstitial keratitis.

The significance of this work relates mainly to the concept of the 'biological' but not the 'clinical' cure of syphilis. Whether the VDRL, TPI, and FTA-ABS tests are nonreactive or reactive, the outcome of treatment with penicillin cannot be regarded as a 'biological' cure if $T$. pallidum-like organisms can still be demonstrated in the tissues.

In general, the clinical results of treating syphilis with penicillin have been very satisfactory, although a number of failures have been reported through the years, as when Rajam and Rangiah (1955) reported a case of treatment-resistant syphilis from the Madras Institute of Venereology.

The possibility that $T$. pallidum may have a life cycle of several stages in which the treponemal form is only one which is susceptible to penicillin may be considered as a possible explanation of the persistence of treponemes in treated late cases.

It is to be hoped that these findings will promote interest in fundamental research in other centres. A particular need is the successful culture of $T$. pallidum in an artificial medium which might help to answer many queries in the field of syphilology.

\section{Summary}

A study was conducted into the persistence of $T$. pallidum in the tissues and body fluids of 43 human subjects with syphilis at various stages, forty of whom had received 'adequate' treatment with penicillin. Studies were also carried out on rabbits artificially infected with $T$. pallidum to determine the persistence of treponemes in lymph nodes in untreated animals, animals treated with penicillin and animals treated with cortisone. Methods of examination for the presence of treponemes were the rabbit infectivity test, darkfield microscopy, indirect and direct fluorescent antibody staining, and three methods of silver impregnation. Among 36 successfully infected rabbits, were 26 which were not treated, and persisting treponemes were demonstrated in seventeen by lymph node transfer to normal rabbits; in four of these rabbits treponemes were found in lymph nodes by FA staining. Treponemes could not be found by any method in the nine rabbits treated by cortisone or in the ten rabbits treated with penicillin.

Among the 43 human subjects there were three who had received no treatment; treponemes were demonstrated by the rabbit infectivity test in one case and by darkfield microscopy of aqueous humour and FA staining of lymph node tissue in another case. There were forty patients who had received adequate penicillin treatment; treponemes were found in thirteen cases-in the aqueous humour in seven, in excised lymph nodes in four, in aortic tissue excised at operation in one, and in brain tissue after the post mortem examination of a patient who had died from GPI. Except in one untreated human case, the virulence of the persisting treponemes could not be proved by the animal infectivity test. The significance and implications of these findings are discussed.

The financial support of this investigation by the Indian Council of Medical Research, New Delhi, is gratefully acknowledged.

The free assistance given by W.H.O. in providing special research equipment, reagents, and chemicals is greatly appreciated.

The Government of Tamil Nadu, the Director of Medical Education, and the Dean of the Madras Medical College have given encouragement and facilities to conduct this investigation at the Central V.D. Reference Laboratory of the Madras Institute of Venereology.

The authors wish to express their thanks to Dr. P. N. Rangiah, the Director and Professor of Venereology, and Dr. C. N. Sowmini, Associate Professor of Venereology, for providing valuable clinical material and the staff of the V.D. Clinic and the laboratory for their help in the successful conduct of this enquiry.

\section{References}

Biological Stain Commission (1960) 'Staining Procedures', 2nd ed., revised by H. J. Conn, M. A. Darrow, and V. M. Emmel, p. 264. Williams and Wilkins, Baltimore Christman, E. H., Hamilton, R. W., Heaton, C. L., and HOFFMEYER, I. M. (1968) Arch. Ophthal. (Chicago), 80, 303

Collart, P., Borel, L-J., and Durel, P. (1962a) Ann. Inst. Pasteur, 102, 596

,,$---(1962 b)$ Ibid., 102, 693

$\longrightarrow,-,-$ (1962c) Ibid., 102, 953

- _- _- (1964) Brit. F. vener. Dis., 40, 81

Goldman, J. N., and GIRARD, K. F. (1967) Arch. Ophthal. (Chicago), 78, 47

JayaraJ, A. P. (1964) Indian F. Path. Bact., 7, 128 
MetzGer, M., and Ruczkowska, J. (1962) WHO/VDT/ RES, 62.21

RAjam, R. V., and Rangiah, P. N. (1955) Brit. f. vener. Dis., 31, 25

Rice, N. S. C., Dunlop, E. M. C., Jones, B. R., Hare, M. J., KING, A. J., Rodin, P., Mushin, A., and Wilkinson, A. E. (1970) Ibiä., 46, 1

SMITH, J. L., and IsRaEL, C. W. (1967a) f. Amer. med. Ass., 199,980

,$--(1967 \mathrm{~b})$ Arch. Ophthal (Chicago), 77, 474

- - - (1968) Brit. F. vener. Dis., 44, 109

United States Public Health Service (1964) 'Manual of Serological 'Tests for Syphilis', P.H.S. Publication No 411. U.S. Government Printing Office, Washington, D.C.

Yobs, A. R., Clark, J. W., Jr., Mothershed, S. E., Bullard, J. C., and ARTLEy, C. W. (1968) Brit. $\mathcal{F}$. vener. Dis., 44, 116

- -, Olansky, S., Rockwell, D. H., and Clark, J. W., Jr. (1965) Arch. Derm., 91, 379

\section{Persistance du T. pallidum et sa signification dans la syphilis tardive traitée par la pénicilline et restant positive}

\section{SOMMAIRE}

On a entrepris une étude sur la persistance de $T$. pallidum dans les tissus et les humeurs de $\mathbf{4 3}$ humains atteints de syphilis à différents stages, dont 40 avaient reçu un traitement 'adéquat' par la pénicilline. Des études furent également entreprises chez des lapins expérimentalement infectés avec $T$. pallidum pour rechercher la persistance de tréponèmes dans des ganglions d'animaux non traités, par la pénicilline et d'animaux traités par la cortisone. Les méthodes utilisées pour établir la présence de tréponèmes furent le test d'infectiosité du lapin, l'examen au fond noir, la coloration par fluorescence directe et indirecte et trois méthodes d'imprégnation argentique. Parmi 36 lapins infectés, 26 ne furent pas traités et la persistance de tréponeèmes fut mise en évidence chez 17 d'entre eux par des transferts ganglionnaires à des lapins normaux; dans 4 de ces cas, des tréponèmes furent trouvés dans les ganglions par marquage fluorescent. Les tréponèmes ne purent être trouvés par aucune méthode chez 9 lapins traités par la cortisone ou chez les 10 lapins traités par la pénicilline.

Parmi 43 humains, 3 n'avaient pas reçu de traitement; des tréponèmes furent mis en évidence par l'épreuve de l'infectiosité du lapin dans 1 cas, par l'examen au fond noir de l'humeur aqueuse et par le marquage fluorescent d'un prélèvement ganglionnaire dans un autre cas. 40 malades avaient reçu un traitement approprié de pénicilline; des tréponèmes furent trouvés dans 13 cas-dans l'humeur aqueuse pour 7 cas, dans le tissu des ganglions lymphatiques excisés pour 4 cas, dans le tissu aortique prélevé lors de l'opération dans 1 cas, et dans le tissu cérébral prélevé après la mort chez 1 malade décédé de paralysie générale. Sauf pour un cas humain non traité, la virulence des tréponèmes persistants ne put pas être établie par l'épreuve de l'infectiosité de l'animal. On discute la signification et les conséquences de ces constatations. 